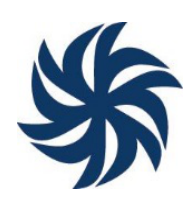

\title{
A ORGANIZAÇÃO INSTITUCIONAL DA CÂMARA DOS DEPUTADOS DO BRASIL E DO URUGUAI E SEUS REFLEXOS NA COMPOSIÇÃO DAS DISCUSSÕES EM PLENÁRIO SOBRE O ABORTO (1985-2016)
}

\section{THE INSTITUTIONAL ORGANIZATION OF THE CHAMBER OF BRAZIL AND URUGUAY'S CHAMBER AND ITS REFLECTIONS IN THE COMPOSITION OF PLENARY ABORTION DISCUSSIONS (1985-2016)}

\section{LA ORGANIZACIÓN INSTITUCIONAL DE LA CÁMARA DE DIPUTADOS DE BRASIL Y DE URUGUAY Y SUS REFLEJOS EN LA COMPOSICIÓN DE LAS DISCUSIONES PLENARIAS DE ABORTO (1985-2016)}

\section{Luis Gustavo Teixeira da Silva*}

Resumo: O objetivo deste texto é demonstrar o modo como a organização institucional das sessões plenárias da Câmara dos Deputados do Brasil e da Câmara dos Representantes do Uruguai, definidas por seus respectivos regimentos internos, estruturou a composição dos pronunciamentos sobre a interrupção voluntária da gravidez, entre os anos de 1985 e 2016. Desse modo, o artigo apresenta a sistematização de algumas regras da atividade legislativa relacionado à fala.

Palavras-chave: Poder Legislativo; Aborto; Brasil; Uruguai.

Resumen: El objetivo de este texto es demostrar cómo la organización institucional de las sesiones plenarias de la Cámara de Diputados de Brasil y de la Cámara de Representantes de Uruguay, definidas por sus respectivos reglamentos internos, estructuró la composición de los pronunciamientos sobre la interrupción voluntaria del embarazo, entre los años 1985 y 2016. De este modo, el artículo presenta la sistematización de algunas reglas de la actividad legislativa relacionada a los discursos.

Palabras clave: Poder Legislativo; Aborto; Brasil; Uruguay.

\begin{abstract}
The objective of this text is to demonstrate how the institutional organization of the plenary sessions of the Chamber of Deputies of Brazil and the Uruguayan House of Representatives, defined by their respective internal regulations, structured the pronouncements on the voluntary termination of pregnancy, between 1985 and 2016. Thus, the article presents the systematization of some rules of legislative activity related to speech.
\end{abstract}

Keywords: Legislative Power; Abortion; Brazil; Uruguay.

*Professor do Departamento de Sociologia e Política da Universidade Federal de Pelotas (UFPel). Doutor em Ciência Política pela Universidade de Brasília (UnB). Atua no estudo da laicidade do Estado no Brasil e no Uruguai, a partir do debate legislativo. E-mail: gustavoteixeira2519@gmail.com. ORCID iD: https://orcid.org/0000-0001-6029-0343 


\section{Introdução}

As investigações sobre a análise de conteúdo das falas, opiniões e comunicados expressos pelos representantes políticos, instituições governamentais e veículos de comunicação, possuem certa tradição em diferentes campos do conhecimento das ciências humanas, as quais sob múltiplos enfoques teóricos produziram um acervo relevante de resultados sobre a realidade brasileira em distintos períodos históricos.

Apesar disso, apenas recentemente estudos sobre os conteúdos expressos nos discursos dos/as parlamentares começaram a ser realizados de maneira mais sistemática, registro aqui as iniciativas realizadas pelo Grupo Democracia e Desigualdades da Universidade de Brasília (Demodê-UnB), e também pelo Grupo de Ideologia e Análise do Discurso da Universidade Federal de Pelotas (IdAD-UFPel). É possível aferir, em boa medida, que essa atenção atual esteja relacionada a três fatores: 1) a disponibilidade de acesso on-line aos Diários da Câmara dos Deputados e/ou Senado Federal do Brasil e de outros países; 2) sistematização das informações da atividade legislativa; e 3) os filtros de rastreamento nestes sites institucionais. Em contextos anteriores uma pesquisa nestes documentos envolveria consideráveis obstáculos, devido ao volume de recursos, tempo e logística para estar in loco no setor de arquivamento dos Diários, assim como a realização integral de sua leitura para seleção e recorte do tema abordado, por fim, o armazenamento das informações obtidas. Portanto, no panorama contemporâneo há notáveis estímulos operacionais para a realização de estudos sobre os pronunciamentos realizados no âmbito do Poder Legislativo.

A análise dos pronunciamentos dos/as parlamentares fornece importantes subsídios para diagnósticos no âmbito legislativo sobre a deliberação, tramitação e construção da agenda em políticas públicas relevantes, por exemplo, nas áreas de: economia, meio ambiente, sustentabilidade e reformas estruturais do Estado. Particularmente com relação aos estudos relacionados aos direitos humanos, investigações dessa natureza apresentam indicadores para entender o avanço, recuo e reações a alguns projetos de lei, que dependendo do caso, como os direitos reprodutivos das mulheres, tramitam por longos períodos nas casas legislativas, sem que sejam levados a esferas de decisão no Poder Legislativo, por conseguinte, sem materialização na forma de uma política pública. As análises sobre as manifestações parlamentares, e seus encaminhamentos, permitem diagnosticar as tensões entre os grupos parlamentares com relação a determinadas agendas e suas formas de condução, em legislaturas específicas ou em uma série temporal mais extensa. A composição de uma base de dados com materiais dessa natureza pode servir como enfoque principal, combinado e/ou complementar a outras fontes.

Diferentemente da análise de conteúdo em outras esferas e documentos, a realização de investigações nos pronunciamentos parlamentares deve atentar para as regras institucionais que organizam o debate no ambiente legislativo. Pois elas são cruciais no entendimento da construção 
do discurso, a centralidade que dará a um determinado tema e a quem se dirige. Já há estudos específicos sobre as sessões plenárias como, por exemplo, a tese de Davi Moreira (2016) sobre os pronunciamentos efetuados durante a sessão do Pequeno Expediente ${ }^{1}$.

Neste mesmo sentido, o objetivo do texto é apresentar uma parte do desenho de minha pesquisa, intitulada Sobre corpos, crucifixos e liberdades: a laicidade do Estado analisada a partir do debate legislativo sobre o aborto no Brasil e no Uruguai (1985-2016), realizada sob orientação da Prof ${ }^{a}$ Flávia Biroli. Especificamente, o propósito é examinar o modo como a organização institucional das sessões plenárias da Câmara dos Deputados do Brasil e da Câmara dos Representantes do Uruguai, definidas por seus respectivos regimentos internos, estruturou a composição das intervenções discursivas sobre a interrupção voluntária da gravidez, entre os anos de 1985 e 2016. O texto apresenta a sistematização de algumas regras da atividade legislativa, bem como aspectos que permitem explicar ou elucidar os resultados da pesquisa. Na primeira seção apresentamos uma breve exposição dos procedimentos metodológicos adotados à sua realização, na segunda seção examinamos as normas institucionais ao exercício da fala em plenário e seus efeitos na conformação dos pronunciamentos.

\section{Aspectos metodológicos}

A metodologia da pesquisa se baseou na análise dos pronunciamentos sobre o aborto, proferidos pelos/as deputados/as que compõem a Câmara dos Deputados do Brasil e a Câmara de Representantes do Uruguai, entre os anos de 1985 e 2016, logo, todas as manifestações de fala realizadas em plenário desde o início do governo civil até os dias atuais. Neste sentido a proposta foi mapear as posições em disputa no tocante aos direitos reprodutivos das mulheres, utilizando como fonte principal de pesquisa os discursos parlamentares.

A comparação entre estes países é relevante por se constituírem em casos opostos, no tocante ao tratamento dos direitos reprodutivos das mulheres. O Uruguai se tornou o único país da região, em período recente, a aprovar uma legislação de descriminalização da interrupção voluntária da gravidez. Já no Brasil verifica-se a ascensão de forças políticas, sociais e religiosas ultraconservadoras, as quais são, em grande medida, responsáveis por conduzir de modo regressivo a discussão sobre o aborto no Poder Legislativo.

A comparação entre Brasil e Uruguai foi realizada a partir de alguns parâmetros. Em primeiro lugar foi efetuada com base em um recorte espacial específico, isto é, a análise dos pronunciamentos proferidos em uma esfera do Poder Legislativo, a Câmara dos Deputados do Brasil e a Câmara de Representantes do Uruguai ${ }^{2}$. Em segundo, foi também aplicado um recorte

\footnotetext{
${ }^{1}$ Esta tese, intitulada "Com a palavra os nobres deputados: frequência e ênfase temática dos discursos dos parlamentares brasileiros" recebeu o Prêmio Capes em 2017, na área Ciência Política/Relações Internacionais.

${ }^{2}$ Esta investigação poderia também ser baseada nos pronunciamentos realizados no Senado de cada país, outra esfera do Poder Legislativo. Contudo, nos concentramos na Câmara dos Deputados em virtude do volume dos dados obtidos, por conseguinte, o alcance das evidências acerca das posições e disputas em torno do aborto, tendo em vista que o
} 
temático, ou seja, entre os diversos assuntos que compõem a agenda parlamentar selecionamos os discursos sobre o aborto. Por último, o recorte temporal foi equivalente para ambos os países. Portanto, apesar das enormes diferenças entre Brasil e Uruguai, tais recortes viabilizam a análise comparativa pelo fato de nos concentrarmos no material produzido pelos/as representantes políticos/as de uma instituição do Estado circunscrita, que possuem função similar no regime democrático ${ }^{3}$.

Esse projeto de pesquisa foi iniciado em 2013 e se concentrou na análise dos pronunciamentos efetuados na Câmara dos Deputados do Brasil, os quais foram inicialmente coletados e analisados no âmbito do projeto: "Direito ao aborto e os sentidos da maternidade: atores e posições em disputa no Brasil contemporâneo", coordenado pela Prof ${ }^{a}$ Flávia Biroli e pelo Prof. Luis Felipe Miguel, desenvolvido na Universidade de Brasília (UnB), com resultados já publicados (MIGUEL; BIROLI, 2016; MIGUEL; BIROLI; SANTOS, 2017; SANTOS; SILVA, 2016; SILVA, 2016; 2018).

O primeiro passo foi a seleção dos pronunciamentos que iriam compor a base de análise. Para isso, elaboramos um conjunto de palavras-chave que permitisse coletar as diferentes formas de construção da fala sobre o aborto. Após testes para experimentá-las no mecanismo de busca no site da Câmara dos Deputados Federais do Brasil, a conclusão foi que os termos mais apropriados seriam os seguintes: "aborto", "abortamento", "interrupção voluntária da gravidez", "interrupção da gravidez", "interrupção voluntária da gestação" e "interrupção da gestação".

A investigação na Câmara dos Representantes do Uruguai foi efetuada após o término da realizada na Câmara dos Deputados do Brasil. Para estabelecer uma análise comparativa foram adotados, na medida do possível, os mesmos parâmetros e procedimentos, salvo por pequenas adequações executadas, principalmente idiomáticas.

Após o processo de seleção, todos os pronunciamentos foram lidos e analisados. Para cada discurso uma ficha no software estatístico Sphinx Lexica ${ }^{4}$ foi preenchida, com 32 variáveis de classificação dos discursos. No anexo I consta o modelo utilizado em ambos os países. A utilização deste instrumento foi de suma importância à sistematização das informações, realizado em três etapas. A primeira etapa consistiu na documentação da fala parlamentar, com o registro da Página, Expediente (BR) / Sessão Plenária (UY) em que o discurso foi pronunciado e Data do discurso nos Diários da Câmara dos Deputados e dos Representantes. Na segunda etapa foram

número de senadores a cada legislatura no Brasil é de 81 e no Uruguai 30, já o número de Deputados é de 513 e 99 , respectivamente.

${ }^{3}$ A sistematização sobre a atividade legislativa é um fator de estímulo às pesquisas com foco neste material. Esta investigação está analisando outros países, como a Argentina, porém a ausência deste mecanismo em países (por exemplo: Colômbia e Paraguai) é fator que impede avanços.

${ }^{4} \mathrm{O}$ software Sphinx Léxica, versão 5.1, permite: a definição de questões fechadas, abertas e numéricas; agrupamento de questões; cruzamento e preparação de variáveis (combinar, transformar e fundir); tabelas de análise simples descritiva, médias, correlações, variância e regressão; tabela léxica; reagrupamento de léxicos; verbatim (extração de textos); elaboração de relatórios descritivos e elaboração de gráficos distintos. 
registradas as informações de identificação do/a parlamentar pronunciante, tais como: Nome, Sexo, Filiação Partidária, Unidade Federativa (BR) / Departamento (UY) pelo qual foi eleito/a, e o número de Mandatos que estava exercendo. A última etapa consistiu em classificar o conteúdo expresso em cada discurso, tais como: as Palavras-chave mencionadas na fala, a Centralidade com que o tema do aborto foi tratado no pronunciamento, Posição Geral sobre o assunto, Posição específica (tipo de ampliação ou restrição ao aborto); Argumentos empregados para sustentar sua posição; o Argumento Principal da fala; o(s) Argumento(s) que o/a parlamentar buscou contestar e/ou refutar; a Auto identificação utilizada como argumento de autoridade para pontuar um lugar de fala (por exemplo: mãe, mulher, médico, sacerdote e jurista); a especificação de algum Fato do momento sobre o qual o pronunciamento se baseou, interno e/ou externo à atividade legislativa, por fim, o arquivamento do Discurso e Observações sobre ele. O recurso tornou exequível a sistematização e cruzamento dos dados obtidos, bem como a construção de panoramas qualitativos e quantitativos de um material composto essencialmente por textos (Em nota de pesquisa, Silva (2017a), explicito a forma de utilização e o papel de cada variável de classificação dos discursos).

\section{A organização institucional para o exercício da fala no ambiente parlamentar}

A partir desses procedimentos, a pesquisa na Câmara dos Deputados do Brasil coletou 1102 discursos e analisou 1078 discursos $^{5}$, proferidos entre janeiro de 1985 e dezembro de 2016. Os dados correspondem ao período que abrange a $47^{\mathrm{a}}$ legislatura até a $55^{\circ}$ legislatura. Na Câmara de Representantes do Uruguai coletamos 352 discursos e analisamos 337, proferidos entre janeiro de 1985 e dezembro de 2016 , entre a $42^{\circ}$ legislatura até a $48^{\circ}$ legislatura.

Inicialmente precisamos pontuar que no Brasil são eleitos 513 deputados federais, para o exercício do mandato em legislatura com duração de 4 anos. No Uruguai são eleitos 99 parlamentares à Câmara de Representantes, para legislatura com duração de 5 anos. Essa composição nos legislativos nacionais foi relativamente constante entre 1985 e 2016, em parte explicam as diferenças na proporção dos discursos pronunciados.

É importante ressaltar também que os discursos foram pronunciados sob uma base legal distinta. No Brasil o Código Penal de 1940, promulgado pelo Decreto-Lei n ${ }^{\circ} 2.848$, estabeleceu os dispositivos jurídicos sobre o aborto, em grande parte, vigentes até os dias atuais. Nesta legislação o ato é enquadrado entre os crimes contra a pessoa e a vida, com punições ao aborto provocado pela gestante e por terceiros, as atenuantes desta lei são: Art. 128 - a ausência de

\footnotetext{
${ }^{5}$ Essa diferença entre o número de discursos coletados e analisados diz respeito ao fato de alguns pronunciamentos terem sido classificados em sua centralidade como Irrelevante, pois empregavam algumas das palavras-chave, mas com outra conotação, por exemplo: "O governo abortou o plano de medidas econômicas". Estes pronunciamentos foram excluídos da análise.
} 
punição quando provocado por médico na circunstância em que não há outro meio para salvar a vida da mãe e quando a gestação é resultado de estupro (BRASIL, 1940). Em 2012 os/as Ministros/as do Supremo Tribunal Federal incorporaram outra atenuante, a descriminalização do aborto em fetos diagnosticados com anencefalia.

Por sua vez, no Uruguai o aborto se tornou delito e criminalizado por meio da Lei n ${ }^{\circ} 9.763$ de 1938. Esta legislação abarcou um número amplo de exceções sobre os quais não se aplicava qualquer tipo de pena, desde que o aborto fosse realizado por um médico, entre as atenuantes estão: gravidez com risco de saúde ou vida da mulher; gravidez consequente de estupro; penúria econômica e honra (Art. 328, incisos 1-5) (URUGUAI, 1938). Esta legislação vigorou até o ano de 2012, quando a interrupção voluntária da gravidez foi descriminalizada.

Esta quantidade total de pronunciamentos está distribuída de modo desuniforme ao longo da série histórica. Como é possível notar no gráfico abaixo, em alguns anos há pouquíssimos registros, ao passo que outros atingem picos de discursos.

Gráfico 1 - Número de discursos sobre o aborto, entre 1985-2016.

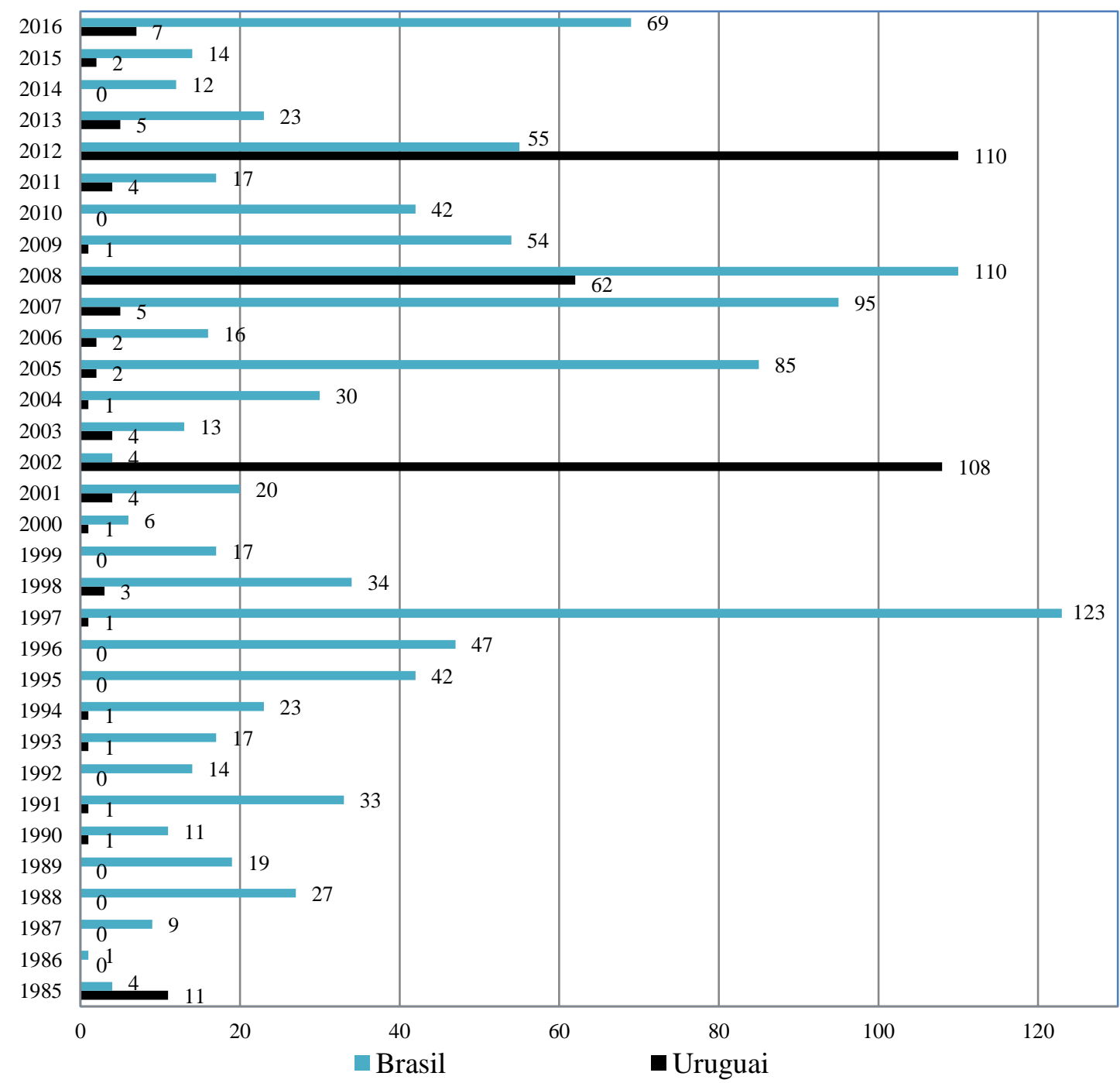

Fonte: Elaboração própria. 
Os resultados apresentados no gráfico permitem diagnosticar que os pronunciamentos no Brasil sobre o aborto apresentam uma frequência relativa em cada ano do período de investigação, embora sejam constatados aumentos e diminuições significativas em alguns anos. Já no Uruguai 83\% dos discursos (280 de 337) foram pronunciados em apenas três anos: 2002, 2008 e 2012. Essa constatação já enuncia algumas características singulares, mas que serão tratadas adiante.

É necessário antes demonstrar que esses pronunciamentos foram classificados e distinguidos de acordo com a centralidade com que a interrupção voluntária da gravidez foi tratada em cada um. A classificação do grau de centralidade é essencial em pesquisas dessa natureza, pois identifica a formatação de cada discurso e também o fato de que eles não possuem as mesmas características, devido ao enfoque concedido por cada parlamentar em sua fala. Assim, na variável "15 - O aborto é tema", era possível assinalar uma entre cinco categorias de preenchimento acerca da centralidade, são elas: $1^{\circ}$ focado, quando a matéria era o ponto central da fala; $2^{\circ}$ um entre vários, apontada em situações que a questão do aborto era um de outros temas tratados no pronunciamento; $3^{\circ}$ secundário de outro foco, quando o tema era apenas complemento de outro assunto principal; $4^{\circ}$ referência lateral, nas ocasiões em que havia meramente breve citação ou alusão ao aborto; $5^{\circ}$ irrelevante, quando não havia qualquer relação do tema tratado com a questão do aborto ${ }^{6}$. Os resultados desta classificação podem ser analisados na tabela abaixo.

Tabela 1 - Distribuição dos discursos (quantidade de citações e porcentagem) de acordo com a centralidade ao tema do aborto na Câmara dos Deputados do Brasil e Câmara de Representantes do Uruguai, entre 1985-2016.

\begin{tabular}{|c|c|c|c|c|}
\hline \multirow{2}{*}{ Centralidade $\downarrow$ País $\rightarrow$} & \multicolumn{2}{|c|}{ Uruguai } & \multicolumn{2}{c|}{ Brasil } \\
\cline { 2 - 5 } & Q. & $\%$ & Q. & $\%$ \\
\hline Focado & 276 & $78,3 \%$ & 664 & $60,3 \%$ \\
\hline Um entre vários & 2 & $0,6 \%$ & 225 & $20,4 \%$ \\
\hline Secundário de outro foco & 21 & $6 \%$ & 119 & $10,8 \%$ \\
\hline Referência lateral & 38 & $10,8 \%$ & 71 & $6,4 \%$ \\
\hline Irrelevante & 15 & $4,3 \%$ & 23 & $2,1 \%$ \\
\hline TOTAL OBS. & 352 & $100 \%$ & 1102 & $100 \%$ \\
\hline
\end{tabular}

Fonte: Elaboração própria.

Novamente é possível perceber que há profunda diferença nos discursos proferidos quando comparados cada país, desta vez quanto ao modo como foram enunciados nas casas legislativas. Por um lado, o número/percentual de pronunciamentos que se dedicaram integralmente a matéria, no Uruguai ele representa quase a totalidade de discursos proferidos,

${ }^{6}$ Como já dito, estas falas utilizavam os termos com outra conotação. Quando era marcado irrelevante nenhuma outra resposta era registrada. 
porquanto que no Brasil mais da metade. Por outro, no Uruguai é muito baixo o índice de pronunciamentos que trataram da questão do aborto conjuntamente a outros assuntos, de maneira secundária e até mesmo como referência lateral, no Brasil essas formas de mobilização aparecem com maior proeminência nas falas parlamentares.

A organização da atividade legislativa e das sessões plenárias é, em grande medida, a principal explicação para os diferentes resultados referente à dispersão dos discursos ao longo da série história no Brasil e sua concentração em períodos específicos no Uruguai, do mesmo modo explica os resultados aferidos na centralidade ao tema do aborto nos pronunciamentos.

Os espaços destinados ao exercício da palavra na Câmara dos Deputados do Brasil são compostos por cinco sessões plenárias. Na sessão do Grande Expediente, os deputados dispõem de 25 minutos para o exercício da palavra. Cada deputado pode fazer o uso da palavra apenas 3 vezes por semestre (BRASIL, 1989; 2012). Neste espaço ocorrem com maior freqüência os apartes parlamentares. O Pequeno Expediente tem duração de sessenta (60) minutos, os deputados dispõem de cinco (5) para se pronunciarem. Este ambiente é conhecido como "pinga fogo", pois este é um dos principais momentos em que o/a parlamentar pode expressar divergências a medidas adotadas pelo governo ou dissertar sobre fatos ocorridos na sociedade. É possível discursar todos os dias nesta sessão, desde que haja disponibilidade, e que o/a deputado/a solicite à Mesa Diretora (BRASIL, 2012; FOSCHETE, 2007).

As Comunicações Parlamentares e das Lideranças acontecem somente quando há disponibilidade de tempo, isto é, quando não se esgota o tempo do Pequeno e Grande expediente e da Ordem do Dia. O tempo disponível é proporcional ao número de membros das respectivas bancadas, com o mínimo de três (03) e o máximo de dez minutos (10), sem apartes e prorrogação. Por sua vez, a Ordem do dia é organizada pelo Presidente da Câmara dos Deputados com base na agenda mensal, embora possua uma pauta prévia isso não impede que os parlamentares estabeleçam relações com outros temas que julguem importante à sua explanação em relação a matéria em discussão na Ordem do Dia (BRASIL, 1989; 2012; FOSCHETE, 2007).

As três primeiras sessões ordinárias, Pequeno Expediente, Grande Expediente e Comunicações Parlamentares, são livres e sem temática específica, já as duas últimas, Comunicações das Lideranças e Ordem do Dia, exigem precondições, tais como, ser líder do partido $^{7}$ e discursar acerca de uma temática focada, respectivamente.

Há sessões plenárias que acontecem em ocasiões excepcionais. Este é o caso da Comissão Geral, sessão realizada para o debate de matérias relevantes, com a possibilidade da presença de autoridades, especialistas, membros da sociedade civil, e demais pessoas com experiência e conhecimento na matéria. Como podemos observar na Comissão $\mathrm{Geral}^{8}$ há um foco no tema em

\footnotetext{
${ }^{7}$ O líder do partido pode ceder seu espaço de fala para outro/a deputado/a do mesmo partido.

${ }^{8}$ Proposta conjuntamente pelos líderes dos partidos ou por requerimento de um terço da totalidade dos membros da Câmara dos Deputados (Brasil, 2012).
} 
discussão, que fundamenta sua convocação e sua própria realização. Outro caso é a sessão solene e/ou homenagem, que ocorre em virtude de comemorações especiais ou devido à recepção de personalidades, também admitindo convidados à Mesa do Plenário (BRASIL, 2012; FOSCHETE, 2007) $)^{9}$. Na tabela abaixo cruzamos os dados referentes à centralidade do discurso e a sessão plenária em que foi pronunciado.

Tabela 2 - Distribuição dos discursos (quantidade de citações e porcentagem) por sessão plenária da Câmara dos Deputados do Brasil e centralidade do tema, entre 1985-2016.

\begin{tabular}{|c|c|c|c|c|c|c|c|c|c|c|}
\hline \multirow{2}{*}{$\begin{array}{c}\begin{array}{c}\text { Centralidade } \\
\rightarrow\end{array} \\
\text { Expediente } \downarrow \\
\text { Grande } \\
\text { expediente }\end{array}$} & \multicolumn{2}{|c|}{ Focado } & \multicolumn{2}{|c|}{$\begin{array}{l}\text { Um entre } \\
\text { vários }\end{array}$} & \multicolumn{2}{|c|}{$\begin{array}{l}\text { Secundário de } \\
\text { outro foco }\end{array}$} & \multicolumn{2}{|c|}{$\begin{array}{c}\text { Referência } \\
\text { lateral }\end{array}$} & \multicolumn{2}{|c|}{ TOTAL } \\
\hline & 74 & $11,2 \%$ & 60 & $26,7 \%$ & 27 & $22,7 \%$ & 16 & $22,5 \%$ & 177 & $\begin{array}{c}16,4 \\
\%\end{array}$ \\
\hline $\begin{array}{c}\text { Pequeno } \\
\text { expediente }\end{array}$ & 264 & $39,8 \%$ & 87 & $38,7 \%$ & 44 & $37 \%$ & 25 & $35,6 \%$ & 420 & $39 \%$ \\
\hline Ordem do dia & 108 & $16,3 \%$ & 20 & $9 \%$ & 13 & $11 \%$ & 7 & $9,9 \%$ & 148 & $\begin{array}{c}13.8 \\
\%\end{array}$ \\
\hline Comunicações & 133 & $20 \%$ & 51 & $22,7 \%$ & 21 & $17,6 \%$ & 13 & $18,3 \%$ & 218 & $\begin{array}{c}20,2 \\
\%\end{array}$ \\
\hline Homenagem & 4 & $0,6 \%$ & 2 & $0,9 \%$ & 6 & $5 \%$ & 5 & $7 \%$ & 17 & $1,6 \%$ \\
\hline $\begin{array}{c}\text { Comissão } \\
\text { geral }\end{array}$ & 10 & $1,5 \%$ & 1 & $0,4 \%$ & 1 & $0,8 \%$ & 2 & $2,8 \%$ & 14 & $1,3 \%$ \\
\hline Aparte & 50 & $7,5 \%$ & 4 & $1,8 \%$ & 5 & $4,2 \%$ & 1 & $1,4 \%$ & 60 & $5,6 \%$ \\
\hline Votação & 21 & $3,2 \%$ & 0 & $0,0 \%$ & 2 & $1,7 \%$ & 1 & $1,4 \%$ & 24 & $2,3 \%$ \\
\hline TOTAL & 664 & $100 \%$ & 225 & $100 \%$ & 119 & $100 \%$ & 70 & $100 \%$ & $\begin{array}{c}107 \\
8\end{array}$ & $100 \%$ \\
\hline
\end{tabular}

Fonte: Elaboração própria.

Para o propósito de comparação consideramos interessante notar na tabela que a maioria dos discursos foi efetuada em sessões com tempo disponível oscilando entre três e cinco minutos. Este dado corrobora uma tendência também verificada por outras pesquisas, cujo diagnóstico demonstra que as falas na Câmara dos Deputados se caracterizam por intervenções de cunho informativo, celebrações, recado às bases eleitorais sobre a agenda do/a parlamentar e breves tomadas de posição sobre algum assunto. Tudo isso realizado em curto espaço de tempo, muitas vezes aglutinando mais de um tema no pronunciamento ${ }^{10}$ (MOREIRA, 2017).

Inversamente, outro aspecto relevante na tabela é o índice relativamente baixo de pronunciamentos proferidos durante o Grande Expediente. Visto que nesta sessão o/a parlamentar dispõe de mais tempo para dissertar sobre temas de sua escolha, além de somente poder utilizar a palavra três vezes durante o semestre neste espaço, o que significa que terá de eleger agendas que

\footnotetext{
${ }^{9}$ Em ambas as sessões os discursos são realizados majoritariamente pelos/as líderes ou representantes dos partidos (ou bloco) por um tempo de cinco minutos, porém na Comissão Geral há a possibilidade dos/as demais parlamentares discursarem por até três minutos.

${ }^{10}$ Vale ressaltar que algumas sessões, como o Pequeno Expediente, são transmitidas ao vivo em cadeia nacional.
} 
considera prioritárias de serem discutidas em sua fala. Quando analisamos o número de discursos "focados" no Grande Expediente este número, que em sua totalidade já pode ser considerado baixo, cai para menos da metade, representando apenas 74 falas.

A forma como estão organizadas as sessões plenárias ordinárias na Câmara dos Deputados do Brasil permitem a repercussão quase imediata de agendas e fatos externos e internos à sua atividade ${ }^{11}$. O impacto de alguns episódios, internos ou externos, pode ser observado pela elevação na quantidade de discursos nas conjunturas e anos específicos em que ocorreram. Devido a esta característica dos pronunciamentos, acrescentamos à pesquisa no Brasil outra variável na ficha, intitulada "Há algum caso do momento ao qual o discurso faz menção?" ${ }^{12}$, que permitiu classificar com exatidão quando e a forma como estas agendas e fatos incidiram sobre os pronunciamentos. Na tabela abaixo apresentamos as categorias de preenchimento contidas nessa variável e os resultados obtidos.

Tabela 3 - Apresenta em números absolutos e percentuais os casos citados nos discursos, proferidos na Câmara dos Deputados do Brasil, entre 1985-2016.

\begin{tabular}{|c|c|c|c|}
\hline Caso citado no discurso & $\begin{array}{l}\text { Quantidade } \\
\text { de citações }\end{array}$ & $\%$ & $\begin{array}{l}\text { Período de maior } \\
\text { ressonância }\end{array}$ \\
\hline Processo de elaboração da Constituição de 1988 & 35 & $3,3 \%$ & 1987 até 1989 \\
\hline Projeto de Lei 20/91 & 84 & $7,8 \%$ & 1993 até 1998 \\
\hline Proposta de Emenda Constitucional 25/95 & 40 & $3,7 \%$ & 1995 e 1996 \\
\hline Vista de João Paulo II ao Brasil & 11 & $1 \%$ & 1997 \\
\hline Liminar sobre aborto de anencéfalos & 28 & $2,6 \%$ & 2004 \\
\hline Comissão Tripartite & 15 & $1,4 \%$ & 2005 \\
\hline Normas técnicas do Ministério da Saúde & 61 & $5,6 \%$ & 1998 / 2005 até 2007 \\
\hline Projeto de Lei 1135/91 & 80 & $7,4 \%$ & 2005 até 2013 \\
\hline Frentes Parlamentares contra o aborto & 103 & $9,6 \%$ & 2005 até 2009 \\
\hline Marchas em defesa da vida & 31 & $2,9 \%$ & 2005 até 2012 \\
\hline Movimento Brasil sem Aborto & 13 & $1,2 \%$ & 2006 até 2008 \\
\hline Estatuto do nascituro & 39 & $3,5 \%$ & 2005 até 2015 \\
\hline Posicionamento do Ministro José Gomes Temporão & 10 & $0,9 \%$ & 2007 \\
\hline Encontros de Legisladores e Governantes pela Vida & 17 & $1,6 \%$ & 2007 até 2009 \\
\hline Campanha da fraternidade da CNBB & 10 & $0,9 \%$ & 2008 \\
\hline CPI do aborto & 45 & $4,2 \%$ & 2009 até 2009 \\
\hline Aborto de menina de 9 anos e excomunhão dos médicos & 24 & $2,3 \%$ & 2009 \\
\hline Aborto na disputa Presidencial 2010 & 15 & $1,4 \%$ & 2010 \\
\hline Reforma do Código Penal - PL 236/2012 & 17 & $1,6 \%$ & 2012 \\
\hline Julgamento dos anencéfalos no STF & 23 & $2,2 \%$ & 2008/2012 \\
\hline Decisão do STF sobre anencéfalos & 19 & $1,8 \%$ & 2012 \\
\hline STF e o aborto em caso de microcefalia (Zika) & 47 & $4,3 \%$ & 2016 \\
\hline Epidemia Zika Vírus - Casos Microcefalia & 20 & $1,85 \%$ & 2016 \\
\hline Outro & $140^{13}$ & $13 \%$ & ------ \\
\hline Não & 346 & $32,1 \%$ & ------ \\
\hline TOTAL & 1273 & ------ & ------ \\
\hline
\end{tabular}

Fonte: Elaboração própria.

\footnotetext{
${ }^{11}$ Fatos internos são, por exemplo, discursos, iniciativas políticas/jurídicas e projetos de lei provenientes dos poderes constituídos. Já os externos se referem, por exemplo, manifestações políticas ou religiosas e os fatos que acontecem na sociedade e se tornam matéria de discussão dos/as deputados/as.

${ }^{12}$ Esta foi a única situação em que tivemos que criar uma variável específica.

${ }^{13}$ Este número elevado é resultado de nossa decisão em abordar os casos com impacto nos discursos. Destes 140 registros, 62 casos são citados apenas uma vez e nenhum dos demais casos alcança o número de dez citações.
} 
É plausível notar que os principais casos, externos ou internos à atividade legislativa, evocados nas falas dos/as parlamentares são relacionados à aos movimentos contra o aborto e dos grupos religiosos na Câmara dos Deputados, bem como sua atuação para impedir ampliações e/ou regulamentações no direito ao aborto, como no caso da Anencefalia e as Normas técnicas do Ministério da Saúde. Aliás, a proeminência da mobilização religiosa nesta agenda é uma das principais singularidades do debate no legislativo brasileiro, sobretudo a partir dos anos 2000 (SANTOS; SILVA, 2017a; SILVA, 2017b).

Por sua vez, na Câmara de Representantes do Uruguai há três sessões plenárias, são elas: ordinárias, extraordinárias e especiais. Nelas são discutidos apenas o roteiro previamente estabelecido da Ordem do Dia, o que as difere é a atenção que darão para cada tema, as sessões ordinárias são compostas por dez assuntos, as extraordinárias por cinco e as especiais por apenas um assunto (URUGUAI, 2014). Os pronunciamentos analisados no legislativo uruguaio estão distribuídos, segundo a sessão plenária, da seguinte forma: 144 (43,7\% do total de 337) proferidos nas sessões ordinárias; 192 (57\%) em sessões extraordinárias; e apenas um $(0,3 \%)$ em sessão especial.

Para se pronunciarem sobre algum tema que não está na Ordem do Dia, os/as parlamentares dispõem de dois espaços, são eles: Exposiciones Verbales e Exposiciones Escritas. As Exposiciones Verbales ocorrem meia hora antes (media hora previa) do início das sessões ordinárias, e são compostas por seis pronunciamentos com duração total de até cinco minutos cada, estas manifestações servem basicamente para realizar encaminhamentos e para pedidos de inclusão de matérias na Ordem do Dia (URUGUAI, 2014). Caso o/a deputado/a deseje discursar por um período equivalente ao disponível para as falas realizadas durante a Ordem do $\operatorname{Dia}^{14}$, deve apresentar pedido (com precisão sobre o tema) de Exposición Verbal ao Presidente da Câmara, este pedido deverá ser votado pelos/as parlamentares. Em caso de aprovação (por maioria dos votos), o Presidente inclui o pronunciamento na Ordem do Dia em data posterior a solicitação, pois para discursar no mesmo dia deverá também ser anexado um pedido de urgência, que igualmente será submetido à votação (URUGUAI, 2014). As Exposiciones Escritas seguem o mesmo rito de apreciação e votação pelo Presidente e deputados/as.

A partir destes pontos podemos perceber que na Câmara de Representantes do Uruguai os espaços para realização de discursos não relacionados com a Ordem do dia são reduzidos (tanto de tempo como de ambientes) e restringidos por normas regimentais. Isto ajuda a esclarecer muitas interrogações que possam ter surgido, pois explicam o alto percentual de pronunciamentos classificados como "focados" no tema. Uma vez que os/as deputados/as discursaram, na maioria das vezes, quando projetos de lei (PL) para descriminalização do aborto estavam em apreciação

\footnotetext{
${ }^{14}$ Por quinze minutos prorrogáveis até dez minutos, com possibilidade de apartes (URUGUAI, 2014).
} 
na Ordem do dia ${ }^{15}$. Foi assim em 2002, onde em diferentes sessões os/as parlamentares da Câmara de Representantes aprovaram o PL3107/1993, mas que foi vetado no Senado naquele mesmo ano. Já em 2008, o PL 536/2006 foi aprovado em sessão única na Câmara de Representantes e na Câmara de Senadores, porém o Presidente Tabaré Vazquéz (Frente Ampla) vetou a proposição. Em 2012, em diferentes sessões, o PL 567/2011 foi aprovado nas duas casas do Poder Legislativo e sancionado pelo Poder Executivo, chefiado por José Mujica (Frente Ampla), modificando a legislação e estabelecendo em seu primeiro artigo que: "Toda mujer mayor de edad tiene derecho a decidir la interrupción voluntaria de su embarazo durante las primeras doce semanas del proceso gestacional".

De modo algum essas informações permitem concluir que o legislativo uruguaio obstrua deliberações ou as realize de forma inadequada. Apenas indica que há um rito especifico para as sessões plenárias. Isto porque, as deliberações focadas ocorrem preponderantemente nas comissões temáticas. Na verdade, a partir da discussão realizada nelas que seus membros decidirão sobre a viabilidade de levar o tema à apreciação na Ordem do dia (tendo em vista, por exemplo, questões estratégicas) ${ }^{16}$. Dessa forma, quando chega à deliberação nas sessões plenárias a matéria já está em formato de projeto de lei. Aliás, O Poder Legislativo da Argentina é regido por normas muito similares, por esse motivo a discussão legislativa sobre o aborto em 2018 foi histórica, até então jamais tinha havido deliberação sobre o tema ${ }^{17}$.

O exercício e as informações apresentadas possibilitam realizar uma inferência sobre a magnitude dos dados da pesquisa. Neste sentido, utilizando meramente um critério numérico está claro que a quantidade de pronunciamentos proferidos no Brasil (1078) e no Uruguai (337) é assimétrica. Essa diferença pode ser facilmente explicada pela proporcional diferença no número de parlamentares eleitos no Brasil e no Uruguai, 513 e 99, respectivamente, assim como pelos espaços livres disponíveis ao uso da fala. Não obstante, utilizando como parâmetro de comparação a substância dos pronunciamentos, isto é, o modo como foram proferidos, podemos aferir outra percepção acerca da magnitude dos dados. Isto dito, tendo em vista que a maioria das falas efetuadas na Câmara de Representantes do Uruguai apresenta como característica o fato de terem sido pronunciados de maneira focada na matéria, por um tempo de 15 a 25 minutos. No Brasil, os discursos com estas características são proferidos na sessão do Grande Expediente, cujo índice na pesquisa atingiu o número de 74 pronunciamentos (6,9\% do total de 1078), isso equivale a apenas

\footnotetext{
15 A única exceção ocorreu em 1985, quando o tema foi inserido na Ordem do Dia sem que algum projeto de lei estivesse em processo de tomada de decisão. Após alguns pronunciamentos a sessão foi interrompida devido a um tumulto entre os parlamentares por divergência quanto ao assunto.

${ }^{16}$ Seria possível ter analisado os pronunciamentos nas comissões, porém a ausência de uma comissão específica no Brasil sobre o aborto dificultaria a comparação, já que esse é outro ambiente da atividade parlamentar, com regras de funcionamento e restrição à participação de todos/as parlamentares.

${ }^{17}$ Neste ano, na Universidade Federal de Pelotas, analisamos todos os pronunciamentos proferidos na Argentina, com a participação de Amanda Albuquerque, André Vidazinha e Jordana Ramalho.
} 
$31,6 \%$ dos 250 discursos (74,3\% de 337) aferidos com este padrão na pesquisa no Uruguai ${ }^{18}$.

Portanto, a diferença entre os países em números absolutos é inversamente proporcional a diferença em termos de substância das falas no tratamento do assunto. Por um lado, esse diagnóstico apenas revela que cada casa legislativa possui um rito próprio para organizar o modo como os debates se desenvolvem no curso das legislaturas ${ }^{19}$. Por outro lado, esse processo de ponderação da magnitude dos dados promove certo equilíbrio entre realidades, pois dependendo do ângulo de observação é possível estabelecer desnivelamentos em ambos os casos.

\section{Considerações finais}

Neste texto almejei elucidar a importância da análise dos pronunciamentos parlamentares para o entendimento das dinâmicas vigentes no âmbito da política nacional, com foco nos dados de minha pesquisa nos discursos sobre o aborto no Brasil e no Uruguai. A partir disso, procurei apontar a necessidade de examinar e reconhecer a importância da organização institucional do Poder Legislativo sobre o espaço de fala na atividade parlamentar, cujo principal efeito é produzir discursos com características distintas. O relato dessa experiência visa apresentar uma parte relevante da investigação, especialmente pelos desafios na comparação, com o intuito de colaborar em pesquisas nesse campo, e, sobretudo receber contribuições da comunidade acadêmica para equívocos, realinhamento no curso e aperfeiçoamento no processo de compreensão da análise dos pronunciamentos parlamentares.

\section{REFERÊNCIAS}

BRASIL. Câmara dos Deputados. Regimento interno da Câmara dos Deputados. 10. ed. Brasília : Câmara dos Deputados, Edições Câmara, 2012. 415 p. (Série textos básicos; n. 71). Disponível em:

http://bd.camara.gov.br/bd/bitstream/handle/bdcamara/18847/regimento_interno_10ed.pdf?sequ ence=13. Acesso em: 12 nov. 2019.

BRASIL. Decreto-Lei $\mathbf{n}^{\circ}$ 2.848, de 7 de dezembro de 1940. Código Penal. Rio de Janeiro: Presidência da República, 1940. Disponível em: http://www.planalto.gov.br/ccivil_03/decretolei/del2848compilado.htm. Acesso em: 15 jan. 2019.

BRASIL. Resolução da câmara dos deputados no ${ }^{0}$ 17, de 1989. Aprova o Regimento Interno da Câmara dos Deputados. Brasília: Congresso Nacional, 1989. Disponível em: https://www2.camara.leg.br/legin/fed/rescad/1989/resolucaodacamaradosdeputados-17-21setembro-1989-320110-publicacaooriginal-1-pl.html. Acesso em: 12 nov. 2019.

\footnotetext{
${ }^{18}$ Neste caso excluindo os pronunciamentos realizados na media hora previa e os pedidos de esclarecimento (solicitado ao Presidente da Câmara quando o/a parlamentar é citado em outra fala), ambos com duração de cinco minutos, caso contrário o número seria de 276 focados.

${ }^{19} \mathrm{Nada}$ disso autoriza conclusões definitivas sobre a (in)disposição de cada sistema político e dos/as parlamentares em discutir sobre a questão do aborto, para isso seria necessário um parâmetro comparativo sobre o enfoque dado a outros assuntos neste mesmo período.
} 
FOSCHETE, Mozart. Regimento interno da câmara dos deputados - Comentado. 7. ed. Brasília: Editora Vestco, 2007.

MIGUEL, Luis Felipe; BIROLI, Flávia (orgs.). Aborto e democracia. 1 ed. São Paulo: Editora Alameda, 2016. 242 p.

MIGUEL, Luis Felipe; BIROLI, Flávia; SANTOS, Rayani Mariano. O direito ao aborto no debate legislativo brasileiro: a ofensiva conservadora na Câmara dos Deputados. Revista Opinião Pública, Campinas, v. 23, p. 230-260, 2017.

MOREIRA, Davi Cordeiro. Com a palavra os nobres deputados: frequência e ênfase temática dos discursos dos parlamentares brasileiros. 2016. Tese (Doutorado em Ciência Política) Faculdade de Filosofia, Letras e Ciências Humanas, Universidade de São Paulo, São Paulo, 2016.

SANTOS, Rayani Mariano; SILVA, Luis Gustavo Teixeira. O direito à vida como ponto de partida para a análise do debate parlamentar sobre o aborto no Brasil e no Uruguai. In: ENCONTRO ANUAL DA ANPOCS, 40. 2016, Caxambu. Anais [...]. São Paulo: ANPOCS, 2016. Disponível em: http://www.anpocs.com/index.php/encontros/papers/40-encontro-anualda-anpocs/st-10/st29-3/10454-o-direito-a-vida-como-ponto-de-partida-para-a-analise-do-debateparlamentar-sobre-aborto-no-brasil-e-uruguai/file. Acesso em: 12 nov. 2019.

SILVA, Luis Gustavo Teixeira. O debate legislativo sobre o aborto no Brasil e no Uruguai. Revista Teoria \& Pesquisa, São Carlos, v. 26, n. 3, 2017a. Disponível em: http://www.teoriaepesquisa.ufscar.br/index.php/tp/article/view/616. Acesso em: 19 nov. 2019

SILVA, Luis Gustavo Teixeira. Religião e Política no Brasil. Latinoamerica - Revista de Estudios Latinoamericanos, México, v. 64, p. 223-256, 2017b. Disponível em: http://www.scielo.org.mx/scielo.php?script=sci_abstract\&pid=S1665$85742017000100223 \& \operatorname{lng}=$ es\&nrm=iso. Acesso em: 19 nov. 2019

SILVA, Luis Gustavo Teixeira. Laicidade do Estado no Uruguai: Considerações a partir do debate parlamentar sobre o aborto (1985-2016). Religião e Sociedade, v. 38, n. 2, p.53-84, 2018. Disponível em: http://www.scielo.br/pdf/rs/v38n2/0100-8587-rs-38-2-00053.pdf. Acesso em: 19 nov. 2019

URUGUAI. Lei no 9.763, de 28 de janeiro de 1938. Modifica o capítulo IV, título XII do Livro II do Código Penal promulgado pela Lei $\mathrm{n}^{\circ}$. 9.155, de 4 de dezembro de 1933, e declara o aborto como delito. Diário Oficial [da República Oriental do Uruguai], Montevideo, 1938.

URUGUAI. Reglamento de la Cámara de Representantes. Montevideo: Cámara de Representantes, 2014. 272 p. Disponível em: http://www.diputados.gub.uy/docs/reglamento14.pdf. Acesso em: 12 nov. 2019

Artigo recebido em: 2019-08-09

Artigo reapresentado em: 2019-09-23

Artigo aceito para publicação em: 2019-10-22 
APÊNDICE I

Ficha de preenchimento dos discursos sobre o aborto no Brasil e no Uruguai

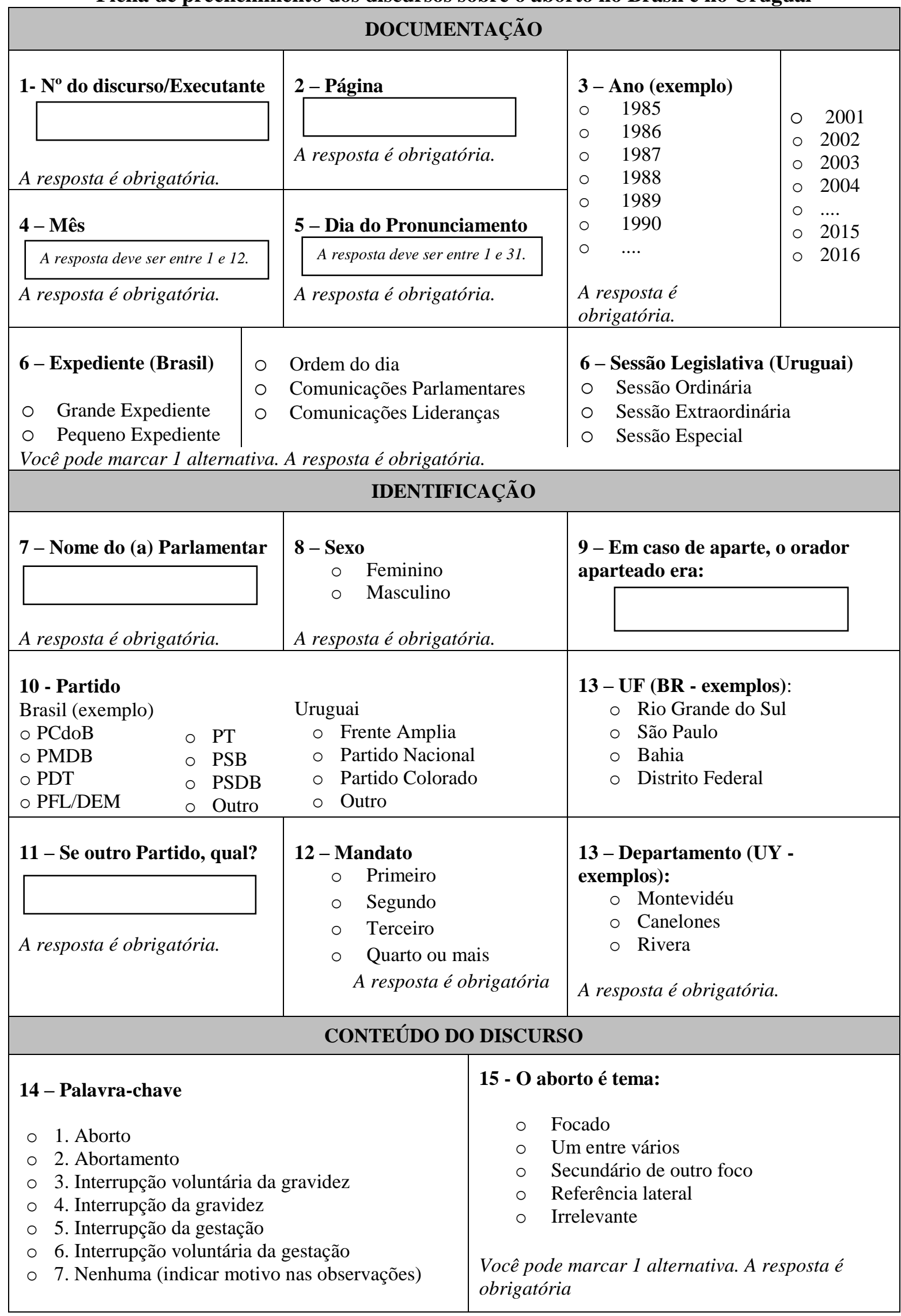


A Organização Institucional da Câmara dos Deputados do Brasil e do Uruguai e seus reflexos na composição das discussões em Plenário sobre o aborto (1985-2016)

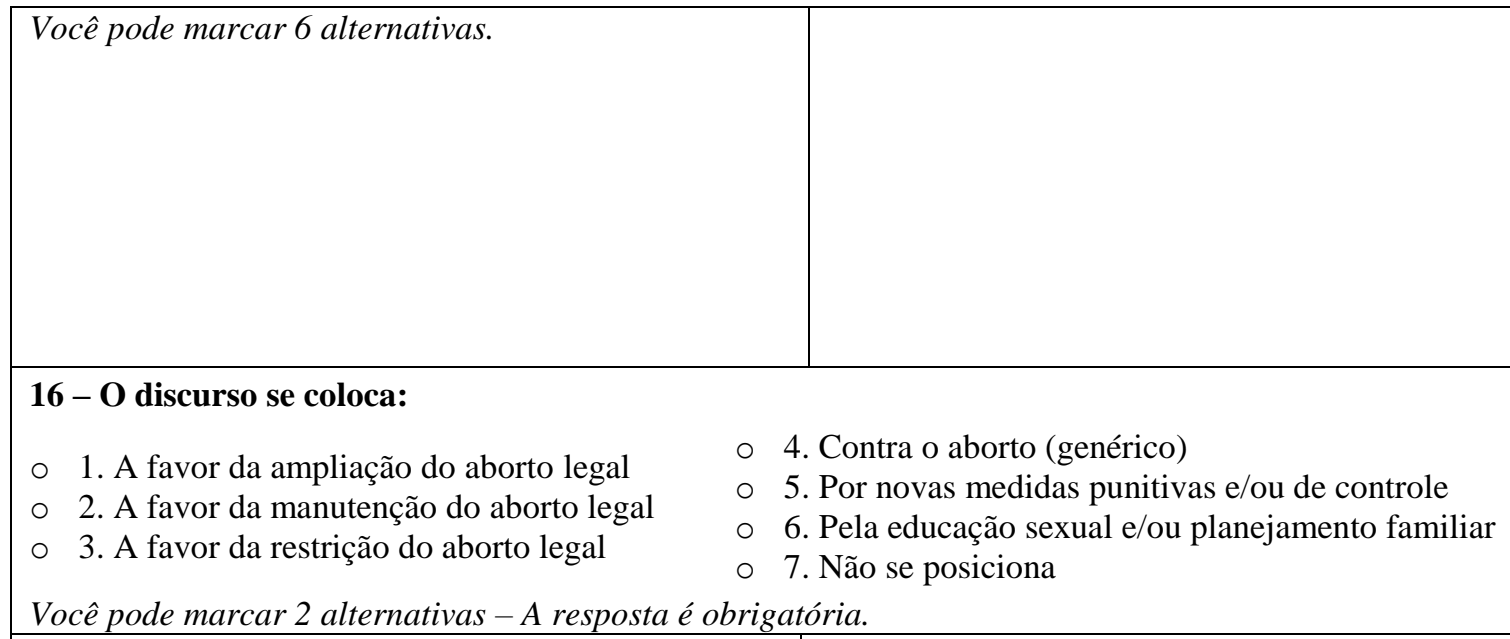

\section{7 - Caso seja a favor da ampliação do aborto:}

- 1. Descriminalização total

- 2. Permissão em caso de inviabilidade do feto

- 3. Ampliação da rede de assistência hospitalar

○ 4. Não indica que tipo de ampliação

○ 5. Outra ampliação

Você pode marcar 4 alternativas
19 - Caso seja a favor da restrição do aborto legal e/ou por novas medidas punitivas:

$\begin{array}{ll}\circ & \text { 1. Proibição total } \\ \circ & \text { 2. Estupro } \\ \circ & \text { 3. Risco de vida da gestante } \\ \circ & \text { 4. Inviabilidade do feto } \\ \circ & \text { 5. Políticas de repressão ao aborto } \\ \circ & \text { 6. Não indica que tipo de restrição } \\ \circ & \text { 7. Outra restrição }\end{array}$

Você pode marcar 6 alternativas -

\section{Se outra ampliação, qual?}

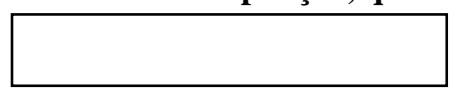

\section{Se outra restrição, qual?}

23 - Qual é o argumento principal do discurso?
25 - O discurso se coloca contra algum tipo de argumento?
21 - Tipos de argumentos assumidos pelo (a) Parlamentar

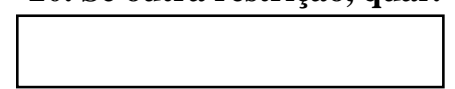

1. Argumentos religiosos

2. Argumentos científicos

3. Aborto é uma questão de saúde pública

4. Liberdade individual

5. Controle da mulher sobre o próprio corpo

6. Argumentos jurídicos

7. Argumentos econômicos

8. Inviolabilidade do direito à vida
9. Injustiça social

○ 10. Argumentos morais (não explicitamente religiosos)

- 11. Argumentos vinculados à opinião pública

$\circ$ 12. Controle da natalidade como estratégia imperialista

- 13. Laicidade do Estado

○ 14. Outro

○ 15. Nenhum

As variáveis 21, 23 e 25 são respondidas com os mesmos argumentos, a diferença é sua função na classificação.

\begin{tabular}{|c|c|c|}
\hline 22 - Outro argumento, qual? & 24 - Outro principal, qual? & 26 - Outro contra-argumento, qual? \\
\hline
\end{tabular}
- Outro principal, qual?
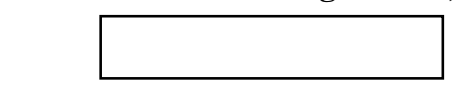

27 - Autoidentificação como argumento de autoridade:
○ 1. Mãe
- 2. Mulher
- 3. Médico (a)
- 4. Secerdote
$\begin{array}{ll}\circ & \text { 5. Jurista } \\ \circ & \text { 6. Cientista } \\ \circ & \text { 7. Outra } \\ \circ & \text { 8. Nenhuma }\end{array}$

28 - Outra identificação, qual?

29 - O discurso se baseia em algum fato do momento? 


\section{Brasil (exemplos)}

- PEC 25/95

- Normas técnicas do MS

- CPI do Aborto

- Marcha em defesa da Vida
○ STF e a Anencefalia o PL 20/91

$\circ$ Microcefalia

o Outro

○ Nenhum

\section{Uruguai (exemplos)}

- PL3107/1993

- Mons. Cotugno

- Outro

- Nenhum

\section{1 - Discurso}

Colocar o texto do pronunciamento na integra.

\section{2 - Observações}

Expor alguma observação sobre o discurso 